\title{
VOLVER A LOS ORÍGENES: LA SOBERANÍA, UN CONCEPTO FUNDAMENTAL PARA COMPRENDER EL DERECHO PÚBLICO
}

\author{
BACK TO THE ORIGINS: SOVEREIGNITY, A FUNDAMENTAL \\ CONCEPT TO UNDERSTAND PUBLIC LAW
}

\author{
Cristóbal Balbontín Gallo ${ }^{1}$
}

\begin{abstract}
RESUMEN: Frente a la crisis social y la violencia asociada a la falta de unidad política heredada del universo feudal, desde sus comienzos la filosofía política moderna concentró su atención en la consolidación conceptual de la soberanía del Estado: única vía para garantizar la seguridad de los individuos y la paz social. Sin embargo, el liberalismo y su preocupación por asegurar los derechos de los individuos frente al Estado se consolida también a partir de la misma época, marcando - del mismo modo- con un rasgo distintivo el pensamiento político moderno. Así se bosquejan dos tendencias contradictorias que acompañarán el nacimiento y desarrollo del Derecho Público contemporáneo. La intención del presente estudio es volver al origen del concepto de soberanía en la filosofía moderna para comprender no solo su desarrollo como elemento decisivo del Derecho Público, sino -paralelamente- para insinuar nuevas bases que permitan proyectar una perspectiva novedosa en el debate contemporáneo sobre el poder constituyente.
\end{abstract}

Palabras clave: Soberanía, liberalismo, república, democracia, poder constituyente.

ABSTRACT: Confronted with a social crisis and violence associated with inherited lack of political unity in the feudal universe, since its inception modern political philosophy focused on the conceptual consolidation of State's sovereignty: the only way to ensure the safety of individuals and peace. However, liberalism and concern for ensuring the rights of individuals against the State is also a distinguishing feature of modern political thought. These two contradictory trends are present in the birth and development of contemporary Public Law. The intention of this study is to return to the origins of the concept of sovereignty in modern political philosophy to encompass not only a key element of Public Law, but also to establish possibilities for a fresh look on the contemporary debate on a constituent power.

Keywords: Sovereignty, liberalism, republic, democracy, constituent power.

\section{INTRODUCCIÓN}

Basta con abrir cualquier manual o tratado de Derecho Administrativo para apreciar cómo los autores se apresuran a conceptualizar el Derecho Público a partir del Estado de Derecho como régimen jurídico que busca asegurar la protección del administrado frente

Doctor en Filosofía por la Universität J.W. Goethe Frankfurt am Main y Université Paris-Ouest NanterreLa Défense. Profesor auxiliar de la Universidad Austral de Chile e investigador asociado al Institut de Recherches Philosophiques (IRePh) de la Université Paris-Ouest Nanterre-La Défense. Correo electrónico: cbalbonting@gmail.com. 
a la Administración. Sin embargo, este ímpetu suele pasar por alto que es la potencialidad del Estado, es decir su poder, lo que permite imponer un sistema normativo de carácter general y obligatorio en el cual el republicanismo reconoce su origen. Ahora bien, esta tensión de fuerzas al interior del Derecho Público está presente desde los albores del nacimiento intelectual del Estado moderno. En efecto, tradicionalmente acordamos ver en Maquiavelo el fundador de la política moderna al anticipar en su obra El Príncipe (1513) las doctrinas de razón de Estado y la necesaria consolidación de la soberanía como fuente del Derecho Público, frente a una Italia fragmentada por luchas intestinas y una crisis social provocada por el vacío de poder. Paradójicamente, es también el concepto de soberanía el que estará al origen de los derechos de los gremios artesanales frente a la herencia feudal en el proyecto de restaurar el estatuto civil antiguo que lleva a cabo Maquiavelo en su Discursos sobre la primera década de Tito-Livio (1512-1517). Estas dos tendencias contradictorias -consolidación del poder soberano y el liberalismo frente al Estado- encontrarán, a su vez, su unidad en un mismo trasfondo individualista que es la doctrina del contrato social, que se prolonga desde Hobbes pasando por Locke hasta Rousseau y que -con sus matices y diferencias- anticipan en buena medida las conquistas y tragedias políticas del siglo XX. De este modo, el propósito del presente estudio es revisar la génesis del concepto de soberanía en la filosofía política moderna y la tensión de fuerzas que la cruza para comprender no solo un elemento decisivo del Derecho Público moderno, sino también para insinuar nuevas posibilidades implícitas al debate contemporáneo sobre el poder constituyente que inflama los espíritus en la actualidad.

\section{LA SOBERANÍA EN EL CORAZÓN DE LO POLÍTICO}

La historia del republicanismo moderno no se limita a la generalidad de la ley, la cualidad objetiva de ciudadano, al nacimiento de la Declaración de Derechos del Hombre y el Ciudadano (1789) o a la consolidación de la laicidad. Hablar de republicanismo reviene también a retrotraer el origen de la ley desde un origen divino a la constitución de un nuevo poder soberano: el pueblo. Soberanía popular que vendrá a designar sobre todo la esencia misma de esta nueva forma de lo político: la república. Así, la caída de la monarquía en Francia hace posible la proclamación de la república en nombre de la soberanía del pueblo el 22 de septiembre de 1792. De este modo, el espíritu republicano busca alzarse en una conciencia de sí del pueblo. Es sobre todo la obra de Rousseau la que permite dar a la soberanía popular el término de república. Jules Ferry, Gambetta, Jaurès, entre otros, son todos políticos que buscan poner en obra el principio fundamental de la soberanía popular que se traduce, ante todo, en el derecho de los ciudadanos a participar libremente en el ejercicio del poder. Si la soberanía pertenece al pueblo es necesario que sea ejercida por el pueblo: se trata de una afirmación de autonomía, la expresión de la capacidad que tiene el pueblo de darse a sí mismo la ley y, por consecuente, de ser libre. Así en el Contrato Social (1762) Rousseau señala que todo gobierno legítimo es republicano ${ }^{2}$. De esta forma la ley no hace sino expresar la legitimidad de la república. El Contrato social instituye entonces la 
soberanía del pueblo como mecanismo por el cual todos se asocian con todos y por el cual la ley está por sobre el hombre. Soberanía del pueblo encarnada en la ley como expresión de una razón pura ligada íntimamente a su dimensión democrática.

Ahora bien, un razonamiento de una naturaleza similar es posible encontrarlo también en Montesquieu, quien en 1748 señaló que el gobierno republicano es aquel donde el pueblo es un solo cuerpo con la potencia soberana ${ }^{3}$. Si la declaración de 1789 establece el principio según el cual toda soberanía reside esencialmente en la nación y que ningún cuerpo, ningún individuo puede ejercer una autoridad que no emane expresamente de la nación, la declaración de 1793 se inspira a su vez directamente de Rousseau al afirmar que la soberanía nacional es "una e indivisible, inalienable e imprescriptible", y elimina la expresión ambigua que señalaba que la soberanía reside "esencialmente" en la nación, privilegiando una expresión absoluta e incondicionada del origen del poder. De manera sucinta la declaración de 1793 permite transferir al pueblo todos los atributos del poder soberano, desplazando hacia la nación y a la democracia todo el principio del Derecho de Estado.

Sin embargo, el concepto de soberanía popular que aparece tan ligado a la dimensión democrática de la República, tiene una historia mucho más compleja que aquella que surge a primera vista. En efecto, aun si en el siglo XVIII el concepto de república está inspirado en una potente aspiración a la libertad, ella está lejos de designar una dimensión democrática de la soberanía. La palabra connota aún de forma bastante tradicional al monarca soberano y a la necesidad de conciliar el orden público con la nueva demanda de libertad de los ciudadanos. Por increíble que pueda parecer, la república podía ser encarnada por un gobierno aristocrático. De hecho, el mismo Montesquieu -uno de los padres del republicanismo moderno- no era republicano y prefería la monarquía constitucional donde el abuso de poder estaba impedido. Así la soberanía se inserta en el corazón de los problemas que perturbaron los espíritus desde Maquiavelo, a través de Jean Bodin hasta Rousseau, y definió un lugar común de la filosofía política desde los tiempos de Maquiavelo hacia adelante.

En efecto, para el autor de El Príncipe, la república designa -siguiendo la historia de Roma- un cuerpo público que posee acentos democráticos, mientras que el principado está dominado por la estatura del príncipe y por el poder unificador de su voluntad de dominación. Ahí donde la filosofía antigua había elevado la sociedad política a ideales, Maquiavelo rompe violentamente con la tradición para develar el verdadero resorte de lo político: el poder independiente de todo resorte moral. Dicho de otro modo: Maquiavelo realiza una cesura entre moralidad y poder. Enseguida el florentino identifica el primer problema de lo político: el poder. Ahí donde Platón hacía inseparables la política y la moral de la función primera de lo político -que era realizar individuos virtuosos y acercarlos al Bien superior-, Maquiavelo opera una ruptura. De este modo para los antiguos no es el origen del poder la pregunta primera de la filosofía política; sino aquella por su fin, por la orientación que debe movilizar la vida en sociedad. En consecuencia, El Príncipe de Maquiavelo no es un tratado teórico sino más bien un manual práctico que busca dar consejos al príncipe de 
cómo gobernar pero, por sobre todo, como conservar el poder. Ciudadano de Florencia, Maquiavelo fue el testigo de luchas violentas y de la suerte trágica de formas políticas impotentes para hacer efectivo un orden público. De ahí el hecho que la característica principal de su obra sea el realismo. No es la bondad ni la probidad lo que determinan la política, sino la violencia. La eficacia del mal justifica la necesidad de apartarse del bien si es necesario:

"Creemos comprender que no es posible para un príncipe, y sobre todo para uno nuevo, el observar en su conducta todo aquello que hace que los hombres sean reputados de gente de bien. Él es frecuentemente obligado de mantener al Estado de actuar de conformidad a la humanidad, a la caridad e incluso la religión misma. Él debe tener el espíritu suficientemente flexible para desviarse hacia todas las cosas según el sentido en que sopla el viento y según los accidentes de la fortuna, cuando así estos lo ordenan; es necesario -como he dicho antes- no separarse del bien si él puede, pero saber entrar en el mal, si la situación lo exige" .

De este modo, con Maquiavelo el lazo entre moral y política se termina. La política es -desde entonces- un asunto de potentia, de soberanía. Gesto de Maquiavelo que -además- anticipa las grandes monarquías absolutas y las doctrinas de razón de Estado.

Ahora bien, corresponderá a Hobbes confirmar y hacer efectivo aquello que en la reflexión de Maquiavelo aún estaba en ciernes. En efecto, al igual que Maquiavelo antes que él, Hobbes vivió bajo el signo del temor. Contemporáneo a la guerra civil inglesa que implicará la ejecución del rey Carlos II y la toma de poder por Olivier Cromwell, Hobbes adquirió una temprana aversión en contra del desorden político y la violencia resultante de ello. De este modo, el Leviatán (1651) es una extraordinaria reflexión política contra la desintegración del orden público. Según ello, Hobbes nos invita a imaginar una situación original de estado de naturaleza en que todos los seres humanos son iguales en libertad. Libertad donde cada cual hace lo necesario no solamente para conservar su vida, sino para expandir su poder. Como ninguna potencia está en condiciones de frenar los apetitos individuales, la guerra de todos contra todos resulta inevitable. La solución para salir de este estado de guerra natural pasa -en consecuencia- por una convención de cada uno con el otro, a través de la cual todos abandonan su derecho natural de autogobierno en beneficio de una potencia soberana. Como Hobbes lo expresa bien: "Se trata de una unidad real de todos en una sola y misma persona, hecha por convención de cada uno con todos, de tal forma que es como si cada individuo dijese a los demás: yo autorizo a este hombre o a esta asamblea de hombres y abandono, por este acto, mi derecho de autogobernarme a condición que tú abandones tu derecho y autorices todas estas acciones de la misma manera. Así es posible la multitud unida en una sola persona llamada Estado (civitas). Tal es la generación de este gran Leviatán, o más bien (para hablar en forma deferente) de este Dios mortal, al cual debemos bajo el Dios inmortal nuestra paz y nuestra defensa"'.

Maquiavelo (1995) p. 440.

Hobbes (2000) p. 288. 
De esta forma, para que el ser humano logre salir del estado de naturaleza es necesario imponer sobre él la potencia del Estado a través de este contrato social. Solamente de esta forma la guerra de todos contra todos acampa.

Podemos sin embargo ver, junto a esta justificación liberal sobre el poder, la justificación del absolutismo. En efecto, para que la solución de esta guerra de todos contra todos sea eficaz, es necesario que la potencia establecida en el Estado sea sin límites. El Estado de Hobbes se siente justificado a hacer todo lo que estime necesario para preservar la paz. Como lo señala Hobbes:

"En virtud del poder [autoritas] conferido por cada ciudadano, el Estado dispone de tanta potencia y de fuerza reunida en él que, por el terror que inspira, puede conformar la voluntad de todos en vista de la paz al interior y frente a los enemigos exteriores. En él reside la esencia del Estado que es (para definirlo) una persona una, del cual los actos tienen por autor (...) cada uno de los miembros de esta gran multitud con el fin que este ente utilice los medios y la fuerza que estime para lograr la paz y la defensa común. Aquel que es depositario de esta personalidad es llamado soberano, y decimos de él que tiene potencia soberana; fuera de él, cada uno es su súbdito"6.

Así, la pregunta por lo político pasa por el establecimiento de una soberanía absoluta capaz de asegurar nuevas libertades. Sin soberanía, solo hay descomposición de la política y de la sociedad. "Autoritas non veritas facit legem" nos recuerda Hobbes?. De este modo, el autor inglés practica una cisión (que comenzó ya Maquiavelo) entre política y moral, para hacer de la cuestión de la soberanía el corazón de lo político.

\section{GÉNESIS DE LA DOCTRINA RACIONAL DE UN PODER LIMITADO: LA SOBERANÍA REPUBLICANA}

Sin perjuicio de lo señalado con anterioridad, será el mérito de Jean Bodin la debida conceptualización del principio de soberanía en los Seis Libros de la República (1576): "La República es un derecho de gobierno de una diversidad de individuos con aquello que tienen en común: la potencia soberana"8.

Utilizando las metáforas de la navegación, Bodin caracteriza el Estado más bien por su fuerza que por su contenido, lo que constituye un cambio de fondo en relación con la filosofía política clásica: "Del mismo modo que el navío no es más que madera sin forma de navío cuando falta la quilla, el arco y la cubierta, la república sin soberano (que une a todos sus miembros como parte en un solo cuerpo) ya no es república" .

La república se caracteriza -entonces- por la soberanía. Esta última designa la potencia que -en el Estado- tiene como atributo primordial dar la ley, pero también imponer excepciones a la ley. Luego, la república, la ley y la soberanía son sinónimos y definen el estatus del Estado moderno. La soberanía no es solo el origen sino también el fin

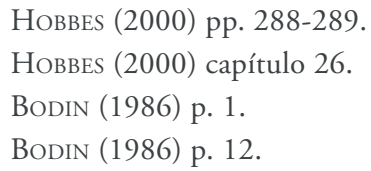


principal de la república bien organizada ${ }^{10}$. La definición más alta de poder es así el poder centralizado, el poder por excelencia.

Sin embargo, la soberanía no apareció de un solo golpe. Ella designa los esfuerzos de los legistas mediavales al servicio del Papa para lograr escindir conceptualmente la autoritas de la pura potestas señorial, que tiene su origen en la violencia feudal. Dicho de otro modo, era necesario resolver conceptualmente un poder que hasta ese entonces aparecía confundido con la fuerza, y separar el poder legítimo de aquel que no lo era. Ahora bien, Bodin oportunamente comprendió que en esta distinción había una renovación significativa de la reflexión política. Luego, la soberanía debía devenir la "buena” potentia o la transposición del poder con un "fin", que Aristóteles asignaba como el vivir virtuoso de los hombres en la polis. No obstante lo anterior, nos encontramos aún en un registro cercano a Maquiavelo, que veía en la cuestión de la adquisición y conservación del poder un efecto positivo de la situación real de la polis. Sin perjuicio de ello, Bodin retoma y corrige la noción de imperium justamente para atacar las formas desnudas de violencia o señorío. En efecto, este imperium para Bodin es identificado al despotismo, es decir, al régimen donde se ejerce el poder en vista del interés privado y donde la autoridad se ejerce por la fuerza sobre individuos sometidos. Por su parte en aquello que dice relación con el modelo señorial o feudal, Bodin ve una forma de poder establecido como dominium: es ella en que se "gobierna a los sujetos como el padre de familia a sus esclavos" ${ }^{11}$. De este modo, la monarquía señorial es aquella donde el príncipe es señor de bienes y personas por el derecho de las armas y de la guerra, ya que los señoríos estaban establecidos al comienzo por la pura fuerza o la usurpación. En resumen, contra el poder señorial fundado en la fuerza de la lanza, la afirmación de Bodin es que el poder es soberano porque el poder se expresa a través de la ley como vehículo y encuentra en la legislación su atributo. La relación que se privilegia aquí es de Derecho, donde los hombres no son tenidos por cosas ni esclavos. Como lo recuerda Pufendorf "los hombres no se poseen por institución sino a falta de ella"12.

La potencia soberana es de este modo un oficio, una fracción pública. Ella no pertenece ni a señores ni a los príncipes. Ella es el Estado, una obra racional y racionalizante que contiene un elemento fundamental del pacto social: los derechos individuales o la libertad y propiedad de los sujetos. Ella es entonces también la doctrina de un poder limitado. La

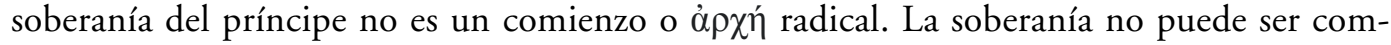
prendida como un comienzo total porque el soberano está inscrito en una ley natural preexistente y renovada que es su verdadero sustrato: "Porque si nosotros decimos que aquel que tiene la potencia absoluta no está sujeto a la ley no sería posible encontrar soberano alguno en el mundo considerando que los príncipes de la tierra están sujetos a las leyes de Dios y de la naturaleza y a las leyes comunes a todos los pueblos"13.

\footnotetext{
Bodin (1986) p. 27.

Bodin (1986) p. 35.

Pufendorf (1989) p. 4.

Bodin (1986) p. 190.
} 
Esta limitación de la soberanía por las leyes divinas naturales y fundamentales constituye la potencia política del Estado republicano como una potencia radicalmente diferente de los regímenes como el señorío y el imperio.

Sin embargo, el pensamiento republicano se vio tempranamente confrontado a un dilema que atraviesa Maquiavelo, Bodin y Hobbes. De un lado, los acentos democráticos se exhiben en la historia de Roma con el respeto de los derechos individuales y la búsqueda de la legitimidad de la soberanía y, del otro, el poder unificador efectivo que implica la voluntad de dominación del príncipe. Dicho de otro modo, nos encontramos confrontados a un dilema entre el ejercicio del poder efectivo y la legitimidad de este poder o -más simplemente aún- entre efectividad y legitimidad.

El mérito reviene a Rousseau en el Contrato Social, de establecer la necesidad de esta potencia superlativa, esta plenitud de poder que son la soberanía y la legitimidad no en Dios, sino únicamente en el pueblo. De esta forma, si la soberanía pertenece al pueblo es necesario que sea ejercida por el pueblo. Allí hay una afirmación de autonomía, de la soberanía del pueblo como origen o ảpxń. Dicho de otro modo, ella es la expresión de la capacidad del pueblo de darse a sí mismo su ley y, por consecuente, de ser libre. Como nos lo recuerda Rousseau: "En lugar de una persona particular, el acto de asociación produce un cuerpo moral y colectivo compuesto de tantos miembros como la asamblea de voces la cual recibe de este mismo acto su unidad, su identidad común, su vida y su voluntad. Esta persona pública que se forma así por unión de todos los otros tomó alguna vez el nombre de la civitas, y toma ahora el nombre de República o cuerpo político. Este último es llamado así por sus miembros, Estado cuando es pasivo, Soberano cuando es activo y Potencia al compararlo con sus semejantes. Frente a sus asociados, toma colectivamente el nombre de Pueblo, del cual cada individuo particular tiene la calidad de ciudadano al participar en la autoridad soberana, y Sujetos, cuando están sometidos a las leyes del Estado"14.

Pertenece entonces a la tendencia natural de la república que la legislación sea la manifestación de su esencia soberana como declaración de la voluntad general del pueblo, teniendo a su vez la felicidad del mismo por finalidad. El atributo por excelencia es entonces el Poder Legislativo como el primer poder entre poderes. La soberanía -como sabemosno se verá reflejada en un Poder Judicial, sino que cederá a la autoridad la ejecución de la decisión legislativa en nombre del bien común a través de la promulgación de la voluntad soberana. El fundamento de la norma encuentra entonces su fundamento en la decisión soberana. Y esto específicamente a través de la deliberación de los representantes del pueblo en el parlamento según Montesquieu.

\section{LA PREEMINENCIA DEL PRINCIPIO DE SOBERANÍA EN EL DERECHO PÚBLICO. ¿UNA CUESTIÓN DE HECHO O DE DERECHO? ALGUNAS CONSIDERACIONES FINALES}

Sin embargo, la historia tomará otro camino, desde Bodin en adelante, se preferirá el modelo de la decisión administrativa encarnada en decretos y órdenes. En efecto, para

14 Rousseau (1947) p.193. 
Bodin es finalmente una decisión soberana y no una deliberación aquello que da fuerza a un acto normativo. Aun si el principal atributo de la norma es la ley, ella depende de un acto de voluntad del soberano. Así, Bodin termina por concebir la ley bajo el modelo de la decisión administrativa originada en la decisión de una autoridad. El hombre de Estado no será aquel que aspira a hacer justicia, sino aquel que desea ejercer una autoridad. Tempranamente, y aun antes de la Revolución, el Estado francés ya había privilegiado la forma del Estado administrativo. Es cierto, originalmente el Estado de justicia era la forma dominante de Estado, pero progresivamente -durante varios siglos- el Estado confiscó la justicia señorial y eclesiástica, justicia que había atraído sobre sí las funciones fiscales, administrativas, de policía e incluso de higiene pública. Recordemos además que en Francia el Chancelier permanece hasta el siglo XVII como el primer personaje del Estado. Sin embargo, con la toma de poder por Colbert en 1661 a través del control general de finanzas, se produce el cambio de naturaleza del Estado: las finanzas acaparan una misión antes entregada a la cancillería. El primer personaje del Estado es ahora el Superintendente de finanzas. El Estado deja de ser un Estado de justicia para devenir un Estado administrativo. Así se organiza un presupuesto centralizado con administradores compuesto de intendentes y prefectos. Por su parte, la revolución de 1789 verá en los jueces un cuerpo de privilegios, razón por la cual se verán limitados a la aplicación estricta de la ley. Pero el Estado administrativo -a pesar de ostentar también una situación discutible desde el punto de vista de los principios revolucionarios- mantendrá su posición privilegiada que arrastraba aún antes de la revolución francesa.

No obstante, si el acto político por excelencia es la decisión de la autoridad, ¿̨no implica ello el riesgo de recaer en un autoritarismo del cual la república intenta escapar frente a la monarquía? Rousseau nos ha protegido, en principio, de todo autoritarismo al establecer que la decisión de la autoridad republicana encuentra el origen de su legitimidad en la voluntad general de la nación, que a través del cumplimiento de las exigencias formales de la ley, busca por fin el bien común. El antiguo despotismo se encuentra así evacuado. Sin embargo, corresponderá al pensamiento de Carl Schmitt -dos siglos más tarde- romper esta ilusión republicana construida por Rousseau.

En efecto, el pensamiento de Carl Schmitt está centrado en el principio de soberanía como en el pensamiento republicano, pero hace inclinar toda la arquitectura conceptual que organiza el pensamiento republicano en el problema de la decisión. Si bien la política desde Bodin hasta Rousseau veía en la soberanía un principio de legitimidad del poder en concordancia con la ley, ella se ve desnudada por Carl Schmitt al mostrar la continuidad de la soberanía con la guerra, y -en consecuencia- con el imperium. Schmitt lleva a cabo la reactualización de la figura del príncipe de Maquiavelo bajo la forma de la autoridad. El hecho fundamental de la soberanía entonces no es la legitimidad, sino la efectividad del poder. Corresponderá entonces a una autoridad tomar una decisión que haga efectivo el orden público. La calidad de este orden público depende de la adquisición y de la conservación del poder por la autoridad así como de la posibilidad de ejercer su voluntad. Este pensamiento -que pone el problema de la conservación del poder al centro de sus preocupaciones- ve en la política la continuidad con la guerra. Desde Montesquieu a Rousseau había un cierto equilibrio en el Derecho del Estado republicano, entre norma y decisión. 
Son las constituciones republicanas las que han permitido el despliegue de la soberanía en un universo pacífico donde la violencia ha logrado apaciguarse. La decisión de la autoridad era vista como la modalidad del ejercicio de la voluntad general según las formas impuestas a través de la ley. Pero Schmitt pone en cuestión este pretendido equilibrio. El pensador alemán vuelve a los orígenes del pensamiento republicano en Maquiavelo y Bodin justamente para rescatar el resto de imperium presente aún en el concepto moderno de soberanía, donde la fuerza es demasiado rápidamente identificada con el concepto de legitimidad. Imperium que es sobre todo visible en la situación de excepción. Como Schmitt lo expresa correctamente, "es soberano aquel que decide en la situación excepcional"15. Luego, la soberanía no es aquella actuación de la autoridad en conformidad a la ley, sino el acto fuera de norma, extraordinario. Es decir, el poder que se muestra sobre todo en la posibilidad de establecer el estado de excepción. Esta decisión es entonces un quiebre: un término y un nacimiento a la vez. Este decisionismo es hecho posible por el poder a partir del espacio que crea y recrea: este es el espacio de la guerra. Lo político se inscribe entonces en la continuación de la guerra respecto de la cual el no sería una verdadera excepción como Bodin, Hobbes y Rousseau lo pensaban.

Así, remontando al origen "absoluto" de la soberanía republicana, Schmitt dirige un reproche al Estado republicano que él llama Estado de Derecho liberal. Para él, el poder del Estado -en el Estado de Derecho liberal- está limitado por las libertades individuales y por el principio de separación de poderes: "Derechos fundamentales y separación de poderes -nos dice Schmitt- caracterizan el contenido esencial de la componente liberal de la Constitución moderna”"16.

Transposición en el dominio del Estado de diferentes elementos que hacen equívoco el componente liberal del Estado moderno republicano como "un Estado caduco y falso"17. Es a partir de lo anterior, que podemos comprender el interés de Schmitt por volver a una teoría de la Constitución pura, donde -como en Maquiavelo o Hobbes- el elemento poder constituya el corazón de la soberanía. Se trata entonces de rehabilitar el núcleo que descansa al fondo del Estado moderno y que constituye su fundamento. Ello significa -a su vez- rehabilitar el poder constituyente: verdadero fundamento del poder que busca realizar la voluntad general del pueblo sin los límites impuros impuestos por la separación de poderes ni por los derechos fundamentales. De forma paradójica, se trata también de rehabilitar de otra forma el pensamiento de Rousseau en el Contrato Social, pero de una forma que Rousseau no avizoró. Es decir, convocar el principio revolucionario y democrático de 1789 para proclamar que la soberanía es la voluntad directa del pueblo y no la ley, que desvía la voluntad general aún si procede de ella. De este modo el decisionismo palpita al centro del corazón conceptual de la soberanía. La concentración de poder en la soberanía deviene en un proyecto indivisible que busca realizarse en la unidad política del Estado moderno en términos enteramente distintos al concepto de unidad política que se obtiene a partir de los derechos individuales en el pensamiento de John Locke.

\footnotetext{
15 Sснмітт (1985) p. 15.

16 Sснмітт (1993) p. 265.

17 Sснмiтt (1993) p. 112.
} 
Luego el desafío implícito al pensamiento de Schmitt es evidente: se trata de oponer por una parte un Estado total (aun si se trata de un Estado democrático total) a un Estado liberal. En resumen, Schmitt realiza una verdadera deconstrucción del Estado moderno republicano para ofrecernos el mismo Estado, pero desde una perspectiva inédita. En este sentido, el perfil del Derecho administrativo contemporáneo en el Estado republicano es para Schmitt la evidencia del enraizamiento en la república del principio de soberanía, es decir, de la preeminencia de la integridad del poder de decisión como hecho de la autoridad, más que un asunto de legitimidad de esta autoridad.

\section{BIBLIOGRAFÍA CITADA}

Bodin, Jean (1986): Les six livres de la République (Paris, Editorial Fayard).

Hobbes, Thomas (2009): Leviathan (trad. Gérard Mairet, Paris, Editorial Gallimard, sexta edición).

Maquiavelo, Nicolas (1995): Le Prince (trad. Gérard Luciani, Paris, Editorial Gallimard).

Maquiavelo, Nicolas (2004): Discours sur la première décade de Tite-Live (trad., Alessandro Fontana, Paris, Editorial Gallimard).

Montesquieu, Charles Louis de Secondat, (1994): L'esprit des lois (Paris, Editorial Nathan).

Pufendorf, Samuel von (1989): Droit de la nature et des gens (trad. Jean Barbeyrac, Caen, Editorial Centre de philosophie politique et juridique).

Rousseau, Jean-Jacques (1947): Du contrat social (Genéve, Editorial du Cheval ailé).

Schmitт, Carl (1993): Théorie de la constitution (trad. de Jean-Louis Schlegel, Paris, Editorial PUF).

Schмiтt, Carl (1985): Théologie politique (trad. de Jean-Louis Schlegel, Paris, Editorial Gallimard). 